\title{
A DISCIPLINA DE FILOSOFIA NO CONTEXTO DA POLÍTICA CURRICULAR NACIONAL BRASILEIRA PÓS 1990
}

\author{
Ana Carolina Camargo Morello ${ }^{10}$ \\ Geraldo Balduíno Horn ${ }^{11}$ \\ Valéria Arias ${ }^{12}$
}

\begin{abstract}
Resumo
O presente artigo sistematiza e problematiza o sentido e a função do ensino de Filosofia no contexto das políticas públicas educacionais a partir da publicação da LDBEN 9394/96, explicitando as principais contradições existentes entre as intencionalidades expressas nas fundamentações, justificativas e concepções dos documentos oficiais e as ações que as traduzem no âmbito das instâncias político-administrativa e escolar, explicitando que as concepções utilizadas como justificativa das reformas educacionais em prol de uma suposta qualidade, ocultam a essência das relações de manutenção do poder hegemônico da sociedade capitalista e suas formas de (con)formação. Reafirma a necessidade não só da manutenção da Filosofia no Ensino Médio como também de seu tratamento didático-pedagógico que a considere como uma disciplina que possui especificidade metodológica, estatuto disciplinar próprio, conteúdos socialmente referendados, podendo contribuir com o processo de humanização e emancipação dos sujeitos.
\end{abstract}

Palavras-chave: Educação, Ensino de Filosofia, Currículo.

\section{THE DISCIPLINE OF PHILOSOPHY IN THE CONTEXT OF THE BRAZILIAN NATIONAL CURRICULAR POLICY AFTER 1990}

\begin{abstract}
This article systematizes and problematizes the meaning and function of Philosophy Education in the public educational policies context as of the LDBEN 9394/96 publication, highlighting the main existing contradictions between the expressed intentions in the foundations, justifications and conceptions of the official documents and the actions that translate them in the scope of political-administrative and school instances, highlighting that the conceptions used as justifications for the educational reforms in favor of a supposed quality, conceal the essence of the relations that maintain the hegemonic power of capitalist society and its forms of (con)formation. The article reaffirms the need of not only maintaining Philosophy in High School but also of its didactic-pedagogical treatment that considers it as a subject that has methodological specificity, its own disciplinary statute, socially referred content, and can contribute to the humanization and emancipation process of the individuals.
\end{abstract}

Key-Words: Education, Philosophy Education, Curriculum.

\footnotetext{
10 Professora Pedagoga da Rede Estadual de Educação do Paraná. Membro do Nesef UFPR. Mestranda em Educação (UFPR). E mail: anamorello@gmail.com

11 Professor Doutor (USP). Docente da UFPR e Coordenador do Nesef UFPR. $E$ mail: geraldobalduino.ufpr@gmail.com

12 Professora Doutora (UFPR). Docente da Rede Estadual de Educação do Paraná. Membro do Nesef UFPR. E mail: arias val@yahoo.com.br
} 


\section{Introdução}

A educação pública no atual contexto político, econômico e social brasileiro é fortemente marcado por retrocessos de todas as ordens. Diante desse cenário, o entendimento de que a educação é uma possibilidade para "superar os graves antagonismos estruturais de nossa sociedade" (MÉSZÁROS, 2008, p. 24) é, ao nosso ver, essencial para refletirmos a respeito da escola, da cultura escolar e suas formas de organização. Além disso, entende-se que a educação escolar consiste no processo de humanização do homem por meio do trabalho educativo.

Humanização esta, que deve objetivar a emancipação e o pensamento crítico, assim como buscar formas de resistência e superação da alienação. "Lutar contra a alienação é lutar por reais condições para todos os seres humanos de desenvolvimento da individualidade à altura das máximas possibilidades objetivamente existentes para o gênero humano" (DUARTE, 2013, p. 14).

Partindo desse pressuposto, o presente artigo tem o intuito de apresentar a análise das orientações curriculares estabelecidas para a disciplina de filosofia após a publicação da Lei de Diretrizes e Bases da Educação Nacional (LDBEN) n 9.394/1996, explicitando as contradições existentes entre o texto expresso nos documentos oficiais do currículo e as ações que pretensamente as traduzem no âmbito das instâncias político-administrativas.

\section{Orientações curriculares nacionais do texto ao contexto}

As primeiras orientações curriculares elaboradas após a promulgação da LDBEN n 9.394/96 foram os Parâmetros Curriculares Nacionais (PCN), a princípio para o Ensino Fundamental, em 1997 e posteriormente para o Ensino Médio, em 2000. Os PCN foram elaborados com base em um relatório da Comissão Internacional sobre Educação para o século XXI, da UNESCO intitulado "Educação: um tesouro a descobrir"13. Neste documento, Jacques Delors ${ }^{14}$ expõe as principais ideias e ideologias dos organismos internacionais, que apresentam a educação como uma salvação à todas as mazelas sociais. No entanto, apesar do bonito e atraente discurso, que ressalta a educação "como um trunfo indispensável para que a humanidade tenha a possibilidade de progredir na consolidação dos ideais da paz, da liberdade e da justiça social” (DELORS, 2010, p. 5), as reformas educacionais propostas por

\footnotetext{
${ }^{13}$ O relatório, de 1996, foi publicado no Brasil somente em 1999.

${ }^{14}$ Como presidente da Comissão Internacional sobre Educação para o século XXI
} 
tais ideais, apenas tinham/têm a intenção de "ajustar a escola às demandas do mercado, ou seja, aos interesses hegemônicos de manutenção das condições de acumulação do capital" (MALACHEN, 2016, p. 3).

Nesse sentido, a preocupação principal das pedagogias do 'aprender a aprender' (DUARTE, 2011) não é com a "transmissão do conhecimento, mas sim com a preparação dos jovens para um futuro imprevisível” (DUARTE, 2016, p. 23), o que acaba por explicitar as estratégias do projeto neoliberal de educação, amparadas pela seletividade e precariedade do processo de ensino-aprendizagem, onde o que importa realmente, não é um processo de formação que vise a autonomia e a emancipação, mas que 'ensine' aquilo que é básico: "ler, escrever e contar" (DELORS, 2010, p. 15). É nessa perspectiva que, tanto as reformas educacionais, como as orientações curriculares foram estabelecidas, desde a publicação da LDBEN, até o atual momento histórico, o que será apresentado a seguir.

\section{Parâmetros Curriculares Nacionais}

Os Parâmetros Curriculares Nacionais (PCN) tiveram sua primeira publicação em 1997 em um total de 10 volumes, relativos ao ensino fundamental, mais especificamente $1^{\mathrm{a}} \mathrm{a}$ $4^{\mathrm{a}}$ séries.

No volume 1, denominado "Introdução aos Parâmetros Curriculares Nacionais" (BRASIL, 1997b), o texto anuncia o compromisso assumido internacionalmente "na luta pela satisfação das necessidades básicas de aprendizagem para todos, capazes de tornar universal a educação fundamental e de ampliar as oportunidades de aprendizagem para crianças, jovens e adultos" (p. 14). No entanto, ao justificar a necessidade de se estabelecer a reforma curricular proposta, aponta a "grande insatisfação com o trabalho realizado pela escola" (Ibidem, p. 17) devido aos elevados índices de evasão e repetência. Essas questões são apresentadas com gráficos e estatísticas que ilustram as afirmações realizadas, culpabilizando os sistemas educacionais e as instituições escolares por uma má qualidade no ensino e também por uma incapacidade em garantir que os estudantes não abandonassem os estudos.

Uma das principais inspirações para a elaboração dos PCN foi a reforma curricular da Espanha (1990), cujo um dos principais coordenadores foi César Coll, que prestou assessoria técnica para o Ministério da Educação durante a elaboração do documento brasileiro.

De acordo com a análise de Moreira (1997), César Coll, a partir de uma perspectiva construtivista, concebe currículo e aprendizagem de forma cognitivista e psicologizante, priorizando o como (aprender e fazer) em detrimento das discussões sobre os conteúdos do ensino, contribuindo assim 
para despolitizar a pedagogia e a escola, para preservar a noção do conhecimento como um processo biológico e natural (isolado das funções sociais e políticas da escolarização) e para obscurecer as relações de controle e de poder necessariamente presentes no processo educacional. (MOREIRA, p. 100)

Isso significa que a base para a definição de 'habilidades e competências' nos PCN se dá a partir dos processos psicológicos e cognitivos (instrumentais, praticistas e pragmáticos), e não quanto aos conhecimentos e conteúdos indispensáveis para que a escola e a prática político-pedagógica nela realizada, possam promover uma formação humana integral e omnilateral.

Conforme Mello (2014), na perspectiva apresentada pelos PCN e posteriormente na BNCC, "o currículo não é centrado nem no aluno nem no conhecimento, mas na aprendizagem e no resultado, entendido como aquilo que o aluno é capaz de saber e fazer. Por essa razão é também denominado currículo referenciado em competências" (p. 2). Diante disso, a autora evoca as produções da OCDE, afirmando que o conhecimento erudito passa a ser secundário, sendo importante e valioso somente "a possibilidade de operar o conhecimento em situações que requerem aplicá-lo para tomar decisões pertinentes" (Ibidem, p. 8), conforme demonstrado na seguinte passagem do PCN

Os Parâmetros Curriculares Nacionais, tanto nos objetivos educacionais que propõem quanto na conceitualização do significado das áreas de ensino e dos temas da vida social contemporânea que devem permeá-las, adotam como eixo o desenvolvimento de capacidades do aluno, processo em que os conteúdos curriculares atuam não como fins em si mesmos, mas como meios para a aquisição e desenvolvimento dessas capacidades. (BRASIL, 1997b, p. 33)

Outra questão importante a se destacar é a ênfase na formação de sujeitos 'flexíveis', proativos, criativos e adaptáveis, que estivessem 'preparados' para agir em uma sociedade em constante transformação. Quanto a isso, o documento afirma que a educação institucionalizada 'de qualidade' deve

contemplar o desenvolvimento de capacidades que possibilitem adaptações às complexas condições e alternativas de trabalho que temos hoje e a lidar com a rapidez na produção e na circulação de novos conhecimentos e informações, que têm sido avassaladores e crescentes. (Ibidem, ibidem, p. 34) 
Essa premissa reitera, conforme analisado por Shiroma e Evangelista (2003), “o discurso de uma educação salvacionista e redentora que foi concebido como política compensatória na solução dos problemas econômicos e como aliado na administração de eventuais conflitos sociais" (p. 83).

As autoras também chamam atenção para o fato de que a reforma educacional proposta na década de 1990 e explicitada pelos PCN, "construiu tanto a noção de crise educacional quanto a de sua auto-solução. Ou seja, uma educação que se redimiria a si própria" (Ibidem, p. 85). Isso pode ser percebido e confirmado no documento, quando este aborda as condições 'reais' que se encontram as escolas e na centralização do papel do professor enquanto 'recurso humano imprescindível', mas também como responsável pela ineficácia, ineficiência e má qualidade da educação pública institucionalizada.

A situação de precariedade vivida pelos educadores, expressa nos baixos salários, na falta de condições de trabalho, de metas a serem alcançadas, de prestígio social, na inércia de grande parte dos órgãos responsáveis por alterar esse quadro, provoca, na maioria das pessoas, um descrédito na transformação da situação. [...] Com a degradação do sistema educacional brasileiro, pode-se dizer que a maioria das escolas tende a ser apenas um local de trabalho individualizado e não uma organização com objetivos próprios, elaborados e manifestados pela ação coordenada de seus diversos profissionais. (BRASIL, 1997b, p. 35)

É partindo desse pressuposto que os PCN justificam que cada unidade escolar deve, a partir da discussão coletiva e democrática, elaborar um projeto educativo com "a formulação de metas e meios" que devem ser de "co-responsabilidade de todos os membros da comunidade escolar, para além do planejamento de início de ano ou dos períodos de "reciclagem" (Ibidem, idem), deslocando a responsabilidade do Estado para os sujeitos, em uma suposta democratização das ações. Observe-se que, apesar de um discurso de formulação de metas da escola, esta só poderia ser realizada a partir das metas já estabelecidas pelo sistema de avaliação em larga escala.

Quanto à sua estruturação e organização, os PCN afirmam que, baseados nas análises das propostas curriculares oficiais realizada pela Fundação Carlos Chagas, pode-se verificar que as mesmas apresentavam um "descompasso entre os objetivos anunciados e o que é proposto para alcançá-los, entre os pressupostos teóricos e a definição de conteúdos e aspectos metodológicos” (BRASIL, 1997b, p. 41). Diante dessa constatação, o documento assegura que a estruturação dos conteúdos, objetivos, áreas e componentes buscou superar as 
contradições encontradas tendo como fundamento a integração curricular que

assume as especificidades de cada componente e delineia a operacionalização do processo educativo desde os objetivos gerais do ensino fundamental, passando por sua especificação nos objetivos gerais de cada área e de cada tema transversal, deduzindo desses objetivos os conteúdos apropriados para configurar as reais intenções educativas. (Grifo nosso. Ibidem, idem)

Ressalta-se que a palavra "deduzindo" também fortalece a secundarização dos conteúdos, desconsiderando os objetos de estudo de cada disciplina escolar, já que o foco do trabalho na escola, nesta perspectiva, são as habilidades e competências, independente ao que 'elas' se relacionam.

Ainda com relação ao trecho supracitado, pode-se perceber, durante a análise de toda a coletânea dos PCN, que diferentes termos são empregados para designar relações entre conteúdos, habilidades e competências, entre eles: a) integração curricular; b) interdisciplinaridade; c) transversalidade; e d) multidisciplinaridade, como se fossem sinônimos, independente do que significa essas relações e os pressupostos epistemológicos aos quais representam.

Não é objetivo deste artigo aprofundar e conceituar cada um dos termos utilizados pelo documento. No entanto, é importante problematizá-los com o intuito de explicitar os antagonismos neles presente. Nesse sentido, cabe ressaltar que se percebe uma utilização, por parte dos documentos, alicerçada em uma visão "instrumental" e "idealista" das relações entre conhecimentos e 'práticas', que "se funda na busca de alguns elementos comuns que deveriam ser descobertos para se chegar a uma espécie de denominador comum, ou a uma unidade global" (ETGES, 2011, p. 74).

Essa instrumentalização é uma forma de redução de uma ação que se diz interdisciplinar, mas que não passa de uma "junção artificial, burocrática e falsa" (FRIGOTTO, 2011, p. 55) de disciplinas, 'componentes curriculares', 'áreas do conhecimento' e conteúdos. Não obstante, como fazer com que alunos que não conhecem o disciplinar, pensarem 'interdisciplinarmente'? Pela prática ou por qual prática? Esse é, realmente, um problema de organização do currículo? Responder a essas questões extrapola os limites do trabalho aqui apresentado. No entanto, "manter viva a ideia de que a interdisciplina é etapa superior das disciplinas e não negação supostamente superadora delas" (FOLLARI, 2011, p. 135), é condição primeira para superarmos uma visão instrumental, praticista e pragmática do que possa a vir a ser, concretamente, essa tão 'falada' interdisciplinaridade. 
As questões aqui ressaltadas podem ser facilmente observadas na seguinte passagem

Nos Parâmetros Curriculares Nacionais, optou-se por um tratamento específico das áreas, em função da importância instrumental de cada uma, mas contemplou-se também a integração entre elas. Quanto às questões sociais relevantes, reafirma-se a necessidade de sua problematização e análise, incorporando-as como temas transversais. (BRASIL, 1997b, p. 41)

Para além da 'salada epistemológica' apontada como salvação aos problemas de 'fragmentação' do conhecimento, sob a perspectiva de se constituírem como "uma representação ampla e plural dos campos de conhecimento e de cultura de nosso tempo, cuja aquisição contribui para o desenvolvimento das capacidades expressas nos objetivos gerais" (Ibidem, p. 44), a reforma curricular explicitada apenas reitera ideais pós-modernos, que banaliza a razão, a ética e a produção científica e cultural históricas, tendo apenas como referência aquilo que se dá no pragmático e na superfície do acontecimento imediato. Isso acarreta em um processo de ensino-aprendizagem pautado em conhecimentos superficiais e na suposta qualidade que se apresenta com 'bons resultados' nas avaliações em larga escala. Em suma, a "fixação nas aparências, nas superfícies e nos impactos imediatos que, com o tempo, não têm poder de sustentação" (HARVEY, 2017, p. 59).

No ano 2000, a publicação destinada ao ensino médio, foi organizada em quatro partes. A primeira contendo as bases legais da proposta e as outras três relativas às áreas do conhecimento, a saber: a) linguagens, códigos e suas tecnologias; b) ciências da natureza, matemática e suas tecnologias; e c) ciências humanas e suas tecnologias.

A parte I "Bases Legais", inicia a discussão sobre o ensino médio afirmando que esta etapa de ensino exige que a escola possibilitasse aos estudantes uma integração no "mundo contemporâneo nas dimensões fundamentais da cidadania e do trabalho" (BRASIL, 2000a, p. 4), não enquanto perspectiva ontológica, mas produtiva e laboral.

Newton Duarte (2010), ao analisar os limites e contradições da cidadania na sociedade capitalista, afirma que diante da exploração do trabalho e do egoísmo para satisfação das necessidades pessoais, a idealização de uma formação 'cidadã' é insustentável. Para o autor, "enquanto as relações sociais tiverem como mediação universal o dinheiro, o 'cidadão do mundo’ não passará de uma idealização desprovida de real conteúdo" (DUARTE, 2010, p. 83).

Como objetivo na formação do estudante, o documento aponta para "a aquisição de conhecimentos básicos, a preparação científica e a capacidade de utilizar as diferentes 
tecnologias relativas às áreas de atuação" (Grifo do autor. BRASIL, 2000a, p. 5) e justifica a reforma curricular apresentada como necessária, quando considera a expansão nas taxas de matrícula, o perfil dos estudantes atendidos pela rede pública e as exigências estabelecidas pelas mudanças estruturais que decorrem da 'sociedade da informação'. Nesse contexto, afirma que o ensino médio

é a etapa final de uma educação de caráter geral, afinada com a contemporaneidade, com a construção de competências básicas, que situem o educando como sujeito produtor de conhecimento e participante do mundo do trabalho, e com o desenvolvimento da pessoa, como "sujeito em situação" - cidadão. (BRASIL, 2000a, p. 10)

Outro aspecto importante a se destacar, refere-se aos apontamentos realizados pelo documento quando o mesmo discute o "papel da educação na sociedade tecnológica". Neste afirma-se, ainda de forma mais evidente e literal, que as competências "desejáveis ao pleno desenvolvimento humano aproximam-se das [competências] necessárias à inserção no processo produtivo" (Ibidem, p. 11) desvelando a intencionalidade das relações estabelecidas entre educação institucionalizada e as demandas exigidas pelo mercado, com a (con)formação de um cidadão 'autônomo, responsável, flexível e participativo'.

Os PCN se afirmavam como a "Base Nacional Comum", definida e exigida pelo Art. $26^{15}$ da LDBEN 9394/96. No entanto, diferente do que temos hoje com a BNCC, afirmava-se que esta

não pode constituir uma camisa-de-força que tolha a capacidade dos sistemas, dos estabelecimentos de ensino e do educando de usufruírem da flexibilidade que a lei não só permite, como estimula. Essa flexibilidade deve ser assegurada, tanto na organização dos conteúdos mencionados em lei, quanto na metodologia a ser desenvolvida no processo de ensino-aprendizagem e na avaliação. (BRASIL, 2000a, p. 18)

A estruturação curricular proposta pelos PCN não é diferente dos demais documentos orientadores do currículo que serão apresentados neste artigo. Isso significa, que por mais que haja diferenças quanto a nomenclatura utilizada, permanecemos, ao longo de mais de vinte anos, com a mesma proposição de organização curricular por áreas do conhecimento, que "tem como base a reunião daqueles conhecimentos que compartilham objetos de estudo e [...]

\footnotetext{
${ }^{15}$ Os currículos da educação infantil, do ensino fundamental e do ensino médio devem ter base nacional comum, a ser complementada, em cada sistema de ensino e em cada estabelecimento escolar, por uma parte diversificada, exigida pelas características regionais e locais da sociedade, da cultura, da economia e dos educandos. (BRASIL, 1996)
} 
mais facilmente se comunicam, criando condições para que a prática escolar se desenvolva numa perspectiva de interdisciplinaridade" (Ibidem, p. 19).

Com relação ao PCN específico para a área de ciências humanas e suas tecnologias (BRASIL, 2000b), o documento assegura que os conhecimentos de história, geografia, sociologia e filosofia são indispensáveis ao exercício da cidadania e em especial "o desenvolvimento das competências envolvidas na leitura e decodificação do 'economês' e do "legalês"” (p. 4). Percebe-se com esse trecho, a superficialidade com que as questões econômicas e legais são tratadas, apesar de se afirmar como supostamente importante.

Ao abordar "O sentido do aprendizado da área" (Ibidem, p. 5), o texto apresenta uma historicização do que seria a área de humanas e como ela se constituiu, ressaltando a crise da fragmentação do conhecimento que os pressupostos do positivismo acarretou na produção científica, assim como descreve o movimento de exclusão e de ressignificação que as disciplinas das humanidades sofreram na época da ditadura militar no Brasil. Partindo dessas questões, ressalta a necessidade de se buscar uma "síntese entre humanismo, ciência e tecnologia, que implique a superação do paradigma positivista, referindo-se à ciência, à cultura e à história" (Ibidem, p. 7), assim como resgata os ideais salvacionistas da educação, ao reafirmar que "a mão do homem e o teclado do computador estejam ambos a serviço da construção de uma sociedade mais justa e solidária" (Ibidem, p. 8).

Em relação aos conhecimentos de filosofia, os PCN iniciam a discussão apresentando que os professores de filosofia do ensino médio costumam receber indagações dos estudantes quanto à serventia desta disciplina. Não obstante, ainda apontam como uma das causas dessas perguntas, o fato de a educação brasileira ter privilegiado "o conhecimento técnico-científico, em detrimento das 'humanidades', tendo em vista formar um mercado de trabalho de 'especialistas e técnicos', numa resposta 'adequada' à demanda de desenvolvimento e modernização do mundo industrial-tecnológico" (BRASIL, 2000b, p. 44). Diante disso, expõe-se a contradição do desenvolvimento de argumentos do documento, que ora clama por uma formação para o processo produtivo, mas ao tentar justificar o porquê da disciplina de filosofia se mostrar 'desnecessária' para alunos, utiliza de forma negativa aquilo que tenta incutir, ao defender a implementação de uma organização curricular por habilidades e competências.

Cabe ressaltar que, apesar de se ter um capítulo relacionado a filosofia, este não está fazendo a defesa da filosofia enquanto disciplina escolar, apenas discorrendo que os 'conhecimentos de filosofia' devem receber tratamento interdisciplinar e contextualizado, pois, a filosofia possui 
uma natureza, a rigor, transdisciplinar (metadisciplinar), e [...] pode cooperar decisivamente no trabalho de articulação dos diversos sistemas teóricos e conceptuais curriculares, quer seja oferecida como disciplina específica, quer, quando for o caso, esteja inserida no currículo escolar sob a forma de atividades, projetos, programas de estudo etc. (Grifo do autor. BRASIL, 2000b, p. 56)

Com relação as competências e habilidades, o documento elenca as competências específicas da filosofia, a partir de três campos de competências gerais ${ }^{16}$ (representação e comunicação, investigação e compreensão e contextualização sociocultural), do seguinte modo:

Representação e comunicação: Ler textos filosóficos de modo significativo. Ler, de modo filosófico, textos de diferentes estruturas e registros. Elaborar por escrito o que foi apropriado de modo reflexivo. Debater, tomando uma posição, defendendo-a argumentativamente e mudando de posição face a argumentos mais consistentes. Investigação e compreensão: Articular conhecimentos filosóficos e diferentes conteúdos e modos discursivos nas Ciências Naturais e Humanas, nas Artes e em outras produções culturais. Contextualização sócio-cultural: Contextualizar conhecimentos filosóficos, tanto no plano de sua origem específica, quanto em outros planos: o pessoal-biográfico; o entorno sócio-político, histórico e cultural; o horizonte da sociedade científico-tecnológica (BRASIL, 2000b, p. 64).

O documento elaborado e publicizado no ano 2000 foi insuficiente para que as escolas pudessem, de fato, construir suas propostas pedagógicas, não só com relação às ciências humanas, como também às outras áreas do conhecimento devido a amplitude das competências e habilidades descritas em cada um dos componentes curriculares. Por este motivo, em 2002 foram publicadas as "Orientações Educacionais Complementares aos Parâmetros Curriculares Nacionais", denominados como $\mathrm{PCN}+$, com o objetivo de "facilitar a organização do trabalho na escola" (BRASIL, 2002, p. 7).

Ao discorrer sobre a proposta, o documento aponta para a especificidade da escola como cenário real da reforma educacional, afirmando que existem instituições de ensino que se destacam por experiências bem-sucedidas e que estas "não são necessariamente as mais ricas ou mais bem equipadas" (Ibidem, p. 12). Quanto a isso, exprime que o diferencial se dá na relação entre professores, alunos e comunidade em assumir, coletivamente, o

\footnotetext{
${ }^{16}$ Esses campos são iguais para todos os componentes da área de ciências humanas e suas tecnologias.
} 
compromisso. Apresenta a velha máxima de que "vestir a camisa" faz a diferença: "A disseminação de um conceito mais generoso de educação depende de toda a sociedade, e não só de medidas oficiais" (Ibidem, p. 13).

Com um discurso - aparentemente - diferente do seu precursor, os PCN+ expõem a natureza disciplinar dos conhecimentos escolares, mas atentam para o fato de que isso não deve ser considerado como "listas de tópicos". Podemos verificar a situação apresentada com a seguinte passagem:

É preciso reconhecer o caráter disciplinar do conhecimento e, ao mesmo tempo, orientar e organizar o aprendizado, de forma que cada disciplina, na especificidade de seu ensino, possam desenvolver competências gerais. (BRASIL, 2002, p. 15)

No entanto, ao mesmo tempo em que, supostamente, apontam para uma necessidade da especificidade do conhecimento das disciplinas escolares, também, de forma ambígua e antagônica, afirmam que "o que interessa é promover uma ação concentrada no seu conjunto [...], a serviço do desenvolvimento de competências gerais" (Ibidem, p. 18).

Uma das informações que carece de crítica, é quando o documento exemplifica uma ação integrada, demonstrando que

Compreender o sentido dos grandes blocos econômicos e 'da velha e da nova economia' pode ser parte de um mesmo estudo, que permitiria formular hipóteses, propostas e alternativas de solução, em torno da possibilidade de se superar a exclusão social e econômica, dominante em grande parte do mundo. (BRASIL, 2002, p. 19)

Quanto a isso questiona-se em que medida, estudantes do ensino médio, podem apresentar "soluções para superar" a exclusão? Incutir nos sujeitos a ideia de que existe a possibilidade de resolver problemas estruturais de forma individualizada apenas retrata, explicitamente, os ditames para a "Educação do século XXI", tão bem divulgada por Jacques Delors no documento da UNESCO.

Após definir que o objeto da área de ciências humanas consiste em o "amplo estudo

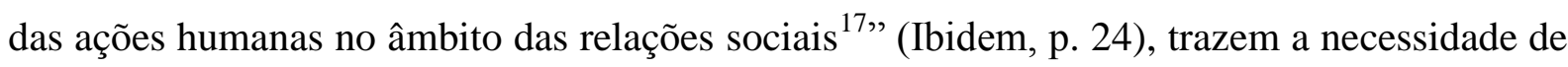
definição de "conceitos estruturadores da área", que permeiam de forma 'transversal' todas as disciplinas que a compõem.

\footnotetext{
${ }^{17}$ Note-se que o "objeto" da área de ciências humanas, entendido a partir dos pressupostos do materialismo histórico-dialético, não deixa de ser todo o conhecimento acumulado historicamente pela humanidade, sendo desnecessária a prerrogativa de divisão burocrática do conhecimento em áreas para se estabelecer 'relações' entre eles.
} 
Após discorrer sobre a importâncias desses "conceitos estruturadores", os PCN+ retomam as competências gerais, definidas pelo PCN da área de Ciências Humanas e suas Tecnologias (BRASIL, 2000b), a saber: a) representação e comunicação; b) investigação e compreensão; e c) contextualização sociocultural, assim como apresentam as competências delas desdobradas para apresentar a articulação destas com os conceitos estruturadores previamente anunciados e assim definidos: o ser, o conhecimento e a ação. (BRASIL, 2002, p. 44)

Ressalta-se, no entanto, que a "forma" explicitada para facilitar "a construção do 'encontro' entre conceitos e competências, estão intimamente relacionados com aspectos metodológicos" (Ibidem, p. 34) e com atividades centradas na resolução de problemas.

A partir desses conceitos estruturadores, as escolas, ao elaborarem seu currículo, deveriam definir um 'eixo temático' que deve "sintetizar uma questão geral central da disciplina que seja significativa para o viver em sociedade e que se relacione com o universo de diferentes sujeitos sociais, em diferentes tempos e lugares" (BRASIL, 2002, p. 40).

Com relação aos procedimentos metodológicos, as orientações priorizam a associação ensino-pesquisa. Essa opção não poderia ser diferente, já que se reitera, no documento, a necessidade de se 'aplicar' atividades baseadas na resolução de problemas. Uma primeira questão a se ressaltar é a incoerência que se pode perceber entre a crítica ao positivismo e a adoção e defesa de um ensino voltado na associação entre ensino/pesquisa, que tem sua base na forma positivista de produção do conhecimento, como o levantamento de "problemas", a elaboração de hipóteses, a busca por dados de diferentes naturezas para confirmar ou refutar as hipóteses previamente levantadas e a "construção" do conhecimento a partir dessas relações de busca, experimentação e aplicação. Outro ponto que merece consideração, referese ao fato de que o pesquisador faz uma problematização, a priori, partindo do que já se conhece sobre um determinado objeto, assim como suas hipóteses partem de seu conhecimento prévio sobre o assunto. Entretanto, como um estudante que ainda não tem conhecimento do objeto/conteúdo, pode elaborar 'problemas', 'hipóteses' ou mesmo 'soluções' sobre ele? Com relação a isso, Saviani (2008) afirma que "o ensino não é um processo de pesquisa. Querer transformá-lo num processo de pesquisa é artificializa-lo" (p.38).

A busca por informações, análise de fontes, observação e dados são importantes e se constituem como atividades essenciais no processo de ensino-aprendizagem. Entretanto, utilizá-lo de forma mecânica, como método a ser aplicado e seguido de forma 'autônoma' por 
estudantes, descaracteriza a função do professor enquanto mediador entre o ato de transmissão e assimilação do conhecimento.

Na especificidade da filosofia, inicia-se o texto fazendo uma problematização acerca das principais questões que permeiam o ensino de filosofia, de antemão, afirmando que definir o que é filosofia, assim como determinar seu objeto e método se configura como problema filosófico (BRASIL, 2002). Diante dessa prerrogativa, o documento assegura que, perante as dificuldades em se estabelecer um objeto, um método e uma definição,

vislumbra-se de forma clara a intenção pedagógica da utilização da Filosofia no Ensino Médio, o que supõe a aceitação de posicionamentos diferentes entre professores de Filosofia na escolha dos conteúdos programáticos, mas não quanto ao 'norte educativo', centrado na formação da cidadania. (BRASIL, 2002, p. 44-45)

Ao expor "O significado das competências específicas da Filosofia" (BRASIL, 2002, p. 46), o documento evoca os escritos de Perrenoud (1999), quando proclama que "mais do que transmitir conhecimentos, o professor deve promover competências gerais. Ou seja, mais do que ensinar, deve "fazer aprender"” (BRASIL, 2002, p. 46), deslocando assim a função do professor daquele que ensina, para aquele que apenas "facilita" os meios para que os próprios sujeitos sejam responsáveis pela "construção" da sua aprendizagem.

Diante do apresentado, observa-se que os Parâmetros Curriculares Nacionais, em suas diversas publicações, são um marco que explicitam a relação entre educação e economia amparada nos pressupostos do neoliberalismo e nas pedagogias ancoradas em teorias pósmodernas.

\section{Orientações Curriculares para o Ensino Médio}

As Orientações Curriculares para o Ensino Médio (OCNEM), foram publicadas em 2006 em três volumes, mantendo a organização curricular por áreas do conhecimento. No entanto, elas se apresentam como necessidade de retomada de discussão de orientações curriculares para o ensino médio, que pudessem aprofundar a compreensão sobre questões que careciam de elucidação por parte dos PCN, como também apontar para alternativas para organização curricular e didático-pedagógica desta etapa da educação básica, contemplando as especificidades de cada disciplina que as compõem (BRASIL, 2006).

Essa mudança na perspectiva da organização curricular do ensino médio se deve, por um lado, às alterações da equipe do Ministério da Educação, já que o Brasil passou por 
eleições presidenciais em 2002, demarcando assim o início do Governo Lula (2003-2011). Entretanto, apesar de apresentar-se de forma diferente e fazendo, mesmo que de forma implícita, uma crítica com relação ao desenvolvimento de habilidades e competências para inserção meramente produtiva de jovens no mercado de trabalho, não houve ruptura com as demandas e pressupostos estabelecidos pelos organismos internacionais para com a área educacional.

Ao apresentar a introdução aos "Conhecimentos de filosofia" (BRASIL, 2006, p. 15), o texto exprime uma concepção e um tratamento diferenciado aos dos PCN com relação à filosofia como componente curricular, pois anuncia que esta deve ser tratada como disciplina obrigatória, afirmando que "isso é condição para que ela possa integrar com sucesso projetos transversais" (Ibidem, idem), contribuindo assim para o pleno desenvolvimento dos estudantes.

Essa ideia é reforçada quando o documento aponta para o fato de que os PCN, apesar de reconhecerem a necessidade de conhecimentos de filosofia, não ofereciam condições curriculares adequadas para sua efetivação. Nesta perspectiva ressalta a necessidade de formação profissional específica, "caso contrário ela [a filosofia] se tornaria uma vulgarização perigosa de boas intenções que só podem conduzir a péssimos resultados” (Ibidem, p. 17). Ainda na perspectiva da necessária formação específica para o professor de filosofia, as OCNEM ressaltam que essa formação específica é importante para que não haja somente alusões a temas 'ditos filosóficos', como questões éticas ou políticas. Nessa prerrogativa, “a Filosofia, cumpre, afinal, um papel formador, articulando noções de modo bem mais duradouro que o porventura afetado pela volatilidade das informações” (Ibidem, idem).

Diante de tais afirmações, o presente documento questiona o desenvolvimento de competências e habilidades sem conteúdos específicos e também o ensino sobre valores e formação para a cidadania, explicitando que "seria criticável tentar justificar a Filosofia apenas por sua contribuição como um instrumental para a cidadania” (BRASIL, 2006, p. 25).

Ao tentar 'definir' uma identidade para a filosofia enquanto disciplina escolar, o documento afirma que é "recomendável que a história da Filosofia e o texto filosófico tenham papel central no ensino da Filosofia" (Ibidem, p. 27), independente de os professores adotarem uma perspectiva temática de organização dos conteúdos, ressaltando a necessidade do conhecimento da tradição e produção filosóficas para possibilitar a base teórica para a compreensão e análise de determinadas questões. 
É importante também ressaltar que existe uma crítica quanto ao caráter utilitário e pragmático dos pressupostos definidos pelos quatro pilares da educação, mesmo que de forma implícita. Isso pode ser percebido no seguinte trecho:

A educação deve centrar-se mais na ideia de fornecer instrumentos e de apresentar perspectivas, enquanto caberá ao estudante a possibilidade de posicionar-se e de correlacionar o quanto aprende com uma utilidade para sua vida, tendo presente que um conhecimento útil não corresponde a um saber prático e restrito, quem sabe à habilidade para desenvolver certas tarefas. (BRASIL, 2006, p. 28)

Entretanto a ruptura com os ideais neoliberais na educação não foi assumida, apresentando apenas uma correlação de forças entre as políticas internacionais e a resistência por parte de um grupo que, naquele momento, estava à frente da elaboração das OCNEM e que notadamente apresentavam uma concepção divergente quanto aos pressupostos epistemológicos e político-pedagógicos da disciplina de filosofia no currículo do ensino médio.

Essa discrepância pode ser observada de forma ainda mais evidente quando o documento discorre sobre as "competências e habilidades em filosofia", pois, ao mesmo tempo em que apresenta a ideia de um ensino por competências como superação de um ensino 'enciclopédico', o faz sob a perspectiva de que essa concepção não pode ser assumida sem “a denúncia entre o perfil do educando esboçado e, por exemplo, certos documentos do Banco Mundial” (BRASIL, 2006, p. 29). Diante disso, reitera que as competências devem ser definidas a partir das matrizes conceituais específicas de cada disciplina, não sendo possível a definição de competências universais, enfatizando que estas "não se desenvolvem sem conteúdos nem sem o apoio da tradição" (Ibidem, p. 30). E ainda:

De fato, no espírito desse documento, a tarefa do professor, ao desenvolver habilidades, não é incutir valores, doutrinar, mas sim "despertar os jovens para a reflexão filosófica, bem como transmitir aos alunos do ensino médio o legado da tradição e o gosto pelo pensamento inovador, crítico e independente". O desafio é, então, manter a especificidade de disciplina, ou seja, o recurso ao texto, sem "objetivá-lo". (Ibidem, idem)

Entretanto, e apesar das tentativas de resistência, mantém as competências e habilidades da área e da filosofia, tal como proposta nos PCN. No entanto, amplia as orientações, ao elencar uma lista de conteúdos (30 tópicos) como sugestões para elaboração 
de materiais didáticos e propostas curriculares com base em "temas trabalhados no currículo mínimo dos cursos de graduação em Filosofia e cobrados como itens de avaliação dos egressos desses cursos" (Ibidem, idem).

Face aos encaminhamentos metodológicos e práticas pedagógicas, privilegia "a centralidade da História da Filosofia" (Ibidem, p. 37), problematiza a não formação específica para a atuação docente e sugere, para além de uma aula expositiva, a utilização de outros recursos didáticos e estratégias de ensino. Isso pode ser percebido, na defesa apresentada pelo documento, quando este afirma que

É preciso, assim, estarmos à altura da elevada qualidade que deve caracterizar o trabalho de profissionais da Filosofia, quando já se pode afirmar, alterando uma antiga diretriz, que "as propostas pedagógicas das escolas deverão, obrigatoriamente, assegurar tratamento disciplinar e contextualizado para os conhecimentos de Filosofia". (BRASIL, 2006, p. 39)

A passagem supracitada demonstra a materialização das pressões realizadas pelos diversos movimentos em prol da institucionalização da filosofia no currículo escolar. No entanto, os primeiros sinais de resistência e luta em estabelece-la não foram suficientes para apresentar mudanças significativas, assim como a ruptura com as diretrizes internacionais, apesar culminar com a alteração da LDBEN 9394/96 pela Lei n $11.684 / 2008$, que tornou obrigatórias as disciplinas de filosofia, e também sociologia, em todas as séries do ensino médio.

\section{Diretrizes Curriculares Nacionais para o Ensino Médio}

As Diretrizes Curriculares Nacionais para o Ensino Médio (DCNEM), publicadas em $2012^{18}$, se contextualizam no momento de garantia legal da obrigatoriedade da disciplina de filosofia no ensino médio, além da determinação da Emenda Constitucional no 59 de 11 de novembro de 2009, que ampliou a obrigatoriedade da oferta da educação básica dos quatro aos dezessete anos.

O conteúdo do texto das DCNEM explicita um movimento de coalisão e de negociação entre as demandas do mercado e também das reivindicações de grupos

\footnotetext{
${ }^{18}$ As DCENEM são compostas pela Resolução no 02/2012 e pelo Parecer no 05/2011. No entanto, como o Parecer no 05/2011 contém o aprofundamento daquilo que foi estabelecido pela Resolução, este será utilizado para análise neste trabalho.
} 
progressistas $^{19}$, resultando em uma miscelânea entre aspectos pós-modernos e neoliberais, com 'pitadas' de princípios ontológicos e histórico-materialista.

Uma questão importante a ser ressaltada é que o documento expõe a necessidade de uma educação com qualidade social, afirmando que o conceito referente ao termo está associado "às mobilizações pelo direito à educação, à exigência de participação e de democratização e comprometida com a superação das desigualdades e injustiças" (BRASIL, 2011, p. 8). Note-se que neste momento, o documento reitera os ideais dos organismos internacionais para a educação, evocando, inclusive, que a UNESCO "defende conceito semelhante" (Ibidem, idem). Cabe ressaltar, porém, que os apontamentos aqui realizados não têm o objetivo de desconsiderar a necessidade da inclusão e justiça social, apenas explicitar as divergências e tentativas de coalizão entre um ideal de educação progressista com pressupostos e orientações neoliberais, que se analisados a partir de suas concepções, tornam impossíveis sua implementação e inócuas as ações que pretensamente as traduzem.

Outra observação importante em se realizar, é que documento também apresenta um breve histórico sobre a trajetória do ensino médio no Brasil, assim como incita discussões que envolvem a diferença entre juventude e juventudes. Quanto a isso, cabe ressaltar a forte presença da perspectiva multicultural, que tem suas raízes nos preceitos pós-modernos.

\begin{abstract}
Apesar de toda a sua tão alardeada abertura para o Outro, o pósmodernismo pode se mostrar quase tão exclusivo e crítico quanto as ortodoxias a que ele se opõe. Pode-se, em geral, falar da cultura humana, mas não da natureza humana, de gênero, mas não de classe, do corpo, mas não da biologia, de fruição, mas não de justiça, do póscolonialismo, mas não da burguesia mesquinha. Trata-se de uma heterodoxia de todo ortodoxa, que como qualquer forma imaginária de identidade precisa de seus bichos-papões e alvos imaginários para manter-se na ativa. (EAGLETON, 1996, p. 28)
\end{abstract}

Partindo desse pressuposto, o que o multiculturalismo nos traz é a ação de pequenos grupos, que de forma isolada tentam se afirmar. Nesse contexto de autoafirmação, perde-se a identidade de classe e de se estabelecer um projeto comum na busca por igualdade e justiça social para todos. Na educação, pelas narrativas individuais, se desqualifica, e mesmo negase, o conhecimento historicamente acumulado, pela defesa dos oprimidos que apresenta um discurso supostamente democrático, anticolonial e multiculturalmente crítico. Reafirma-se, nesse sentido, que não se trata de negar as especificidades dos sujeitos, mas na necessidade

\footnotetext{
${ }^{19}$ Reflexo da política adotada pela então presidente Dilma Rousseff, que deu continuidade nas ações de seu antecessor, o ex-presidente Luís Inácio Lula da Silva.
} 
em se estabelecer ações comuns de enfrentamento aos que se beneficiam com toda essa divisão, quais sejam os grupos hegemônicos.

Ao discorrer sobre os "Pressupostos e fundamentos para um Ensino Médio de qualidade social", as DCNEM definem, como eixo integrador dos currículos do ensino médio, as dimensões do trabalho, ciência, cultura e tecnologia, explicitando uma breve conceituação de cada uma das dimensões e evidenciando que

Uma formação integral, portanto, não somente possibilita o acesso a conhecimentos científicos, mas também promove a reflexão crítica sobre os padrões culturais que se constituem normas de conduta de um grupo social, assim como a apropriação de referências e tendências que se manifestam em tempos e espaços históricos, os quais expressam concepções, problemas, crises e potenciais de uma sociedade, que se vê traduzida e/ou questionada nas suas manifestações. (BRASIL, 2011, p. 20).

Diante disso, demonstra a "unicidade entre as dimensões científico-tecnológicocultural, a partir da compreensão do trabalho em seu sentido ontológico" (Ibidem, idem), sob a justificativa de que este possibilita à escola o "diálogo permanente com a necessidade de compreensão de que estes campos não se produzem independentemente da sociedade, e possuem a marca da sua condição histórico-cultural” (BRASIL, 2011, p. 20).

Além disso, também apresenta os quatro princípios que devem embasar a elaboração dos currículos para o ensino médio, sendo eles: 1) o trabalho como princípio educativo; 2) a pesquisa como princípio pedagógico; 3) os direitos humanos como princípio norteador; e 4) sustentabilidade ambiental como meta universal.

Na descrição destes princípios também é possível observar as posições antagônicas demonstradas ao longo de todo o documento, principalmente ao se analisar as concepções que embasam "o trabalho enquanto princípio educativo" e a "pesquisa como princípio pedagógico". Quanto ao primeiro, o documento declara que

Considerar o trabalho como princípio educativo equivale a dizer que o ser humano é produtor de sua realidade e, por isto, dela se apropria e pode transformá-la. Equivale a dizer, ainda, que é sujeito de sua história e de sua realidade. Em síntese, o trabalho é a primeira mediação entre o homem e a realidade material e social. (BRASIL, 2011, p. 21)

A afirmação supracitada apresenta argumentos evidentemente marcados pela concepção do materialismo histórico-dialético, enquanto a "pesquisa como princípio 
pedagógico" apresenta a produção acelerada de conhecimentos e a sociedade da informação, defendendo que "esse novo modo de ser requer que o aluno, para além de adquirir determinadas informações e desenvolver habilidades para realizar certas tarefas, deve aprender a aprender, para continuar aprendendo" (Ibidem, p. 21-22), o que demonstra, notadamente, a citação a um dos quatro pilares da educação estabelecido por Delors (2010).

É evidente, no entanto, que a abordagem da questão da pesquisa enquanto princípio pedagógico no texto das DCNEM (BRASIL, 2011) é diferente da abordagem da associação ensino-pesquisa defendida pelos PCN (BRASIL, 2002), mas isso não significa que elas sejam divergentes. Pelo contrário, com exceção da utilização de alguns termos com nomenclatura diferentes - e da tentativa de defesa de que é necessário (re)construir conhecimentos - na essência, ambas defendem a mesma posição (im)posta pelos organismos internacionais.

Ao versar sobre a "Identidade e diversificação do Ensino Médio", o documento expressa a necessidade de se desenvolver "possibilidades formativas com itinerários diversificados" (BRASIL, 2011, p. 29). Entretanto, não menciona ou exemplifica as possibilidades de diversificação. É importante ressaltar que a passagem citada já anuncia o movimento que será posteriormente retomado com o PL $\mathrm{n}^{\circ} 6.840 / 2013^{20}$ e com a MP ${ }^{\circ}$ 746/2016, em seguida transformada na Lei ${ }^{\circ}$ 13.415/2017.

Com relação à "Organização curricular do Ensino Médio", o documento inicia a discussão pontuando sobre os problemas referentes à fragmentação do conhecimento devido à concepção disciplinar do currículo, afirmando que existem metodologias e estratégias mais globalizantes (BRASIL, 2011). No entanto, questiona tais metodologias e estratégias ao declarar a "necessidade do aprofundamento dos conceitos inerentes às disciplinas escolares, já que cada uma se caracteriza por ter objeto próprio de estudo e método específico de abordagem" (Ibidem, p. 43).

Diante disso, reforça a ideia de o currículo do ensino médio ser composto por dois momentos, sendo o primeiro referente ao desenvolvimento de conhecimentos por via disciplinar (durante o processo de escolarização) - os quais devem estar organizados em áreas do conhecimento - e o outro por meio de "atividades integradoras" (Ibidem, p. 44) como ampliação do tempo ou contraturno escolar. É importante ressaltar, que diferente das orientações que a precederam, as DCNEM especificam "os componentes curriculares obrigatórios decorrentes da LDB que integram as áreas de conhecimento" (Ibidem, p. 47).

\footnotetext{
${ }^{20}$ Disponível em: http://www.camara.gov.br/proposicoesWeb/fichadetramitacao?idProposicao=602570. Acesso em julho/2018.
} 
Ainda com relação à implementação das DCNEM, o CNE exige que o MEC elabore proposta de "expectativas de aprendizagem dos conhecimentos escolares e saberes que devem ser alcançadas pelos estudantes", mas ressalva que estas "não significam conteúdos obrigatórios de currículo mínimo" (BRASIL, 2011, p. 52). Essas expectativas de aprendizagem transformaram-se, posteriormente na Base Nacional Comum Curricular, conforme veremos no próximo item.

\section{Base Nacional Comum Curricular}

A Base Nacional Comum Curricular (BNCC) teve sua primeira versão publicada para consulta pública em 2015. Este primeiro documento tinha 304 páginas cujo conteúdo apresentava objetivos de aprendizagem e desenvolvimento para a Educação Básica, sendo que para o ensino fundamental e médio, a proposta estava organizada por áreas do conhecimento.

Com relação à especificidade da filosofia, a primeira versão da BNCC organizou os objetivos de aprendizagem da seguinte forma: a) $1^{\circ}$ ano: Introdução ao filosofar, com três objetivos; b) $2^{\circ}$ ano: Opinião, conhecimento e gosto, composto por quatro objetivos; e c) $3^{\circ}$ ano: Condição humana e responsabilidade pelo mundo, com cinco objetivos.

Em 2016, antes da publicação da MP 746/2016, foi divulgada uma segunda versão da BNCC para um novo processo de consulta pública. Esta continha um total de 652 páginas, abrangendo também as três etapas da Educação Básica. Manteve a organização por áreas do conhecimento apresentando componentes curriculares de cada uma, mas agrupava os objetivos de aprendizagem e desenvolvimento em unidades curriculares.

Foram definidos quatro eixos de formação para o ensino médio, a saber: a) Letramento e capacidade de aprender; b) Solidariedade e sociabilidade; c) Pensamento crítico e projeto de vida; e d) Intervenção no mundo natural e social. A proposta era que os eixos estivessem articulados aos objetivos gerais de formação, a partir das dimensões do trabalho, da ciência, da cultura e da tecnologia em todas as áreas e seus respectivos componentes curriculares.

Também foram determinadas, para cada componente, unidades curriculares, com o objetivo de "subsidiar os sistemas de ensino e escolas a construírem combinações" (BRASIL, 2015, p. 487) entre elas. Com relação à filosofia, essas unidades curriculares foram organizadas do seguinte modo: a) Introdução ao pensar filosófico, seus caminhos e culturas, composta por cinco objetivos de aprendizagem e desenvolvimento; b) Opinião, discurso e conhecimento, constituída de cinco objetivos; e c) Condição humana e responsabilidade pelo mundo, desdobradas em cinco objetivos de aprendizagem e desenvolvimento. 
Após a publicação da MP 746/2016 e sua posterior transformação na Lei $\mathrm{n}^{\circ}$ 13.415/2017, foi apresentada em 2017 uma terceira versão do documento bastante diferente quanto à organização e expressões utilizadas. Uma primeira questão a se pontuar refere-se à alteração do termo "objetivos de aprendizagem e desenvolvimento" para "habilidades e competências" retomando grande parte dos princípios contidos nos PCN (1997; 2000a; 2000b; 2002). Uma segunda questão, refere-se ao desmembramento do documento. Em 2017 foi encaminhada e aprovada pelo CNE somente a BNCC da educação infantil e do ensino fundamental, com 472 páginas. Nela foram mantidas a organização do ensino fundamental por áreas do conhecimento, assim como apresentados os componentes curriculares referente a cada área.

Somente em 2018 foi encaminhada ao CNE a versão referente ao Ensino Médio, cujo documento contém 154 páginas, nas quais se apresentam as competências e habilidades referente às áreas do conhecimento. É importante ressaltar que nele, somente as disciplinas de língua portuguesa e matemática têm suas habilidades e competências descritas. Em relação aos itinerários formativos, o documento apenas menciona que haverá um documento próprio para sua orientação e organização. Atualmente, o CNE retornou a BNCC do ensino médio ao Ministério da Educação para revisão, o que impede sua análise de forma mais aprofundada.

No entanto, pela análise do documento encaminhado ao CNE, publicado em versão preliminar, é possível realizar uma comparação acerca de alguns elementos entre a terceira versão da $\mathrm{BNCC}$ referente ao ensino médio e os $\mathrm{PCN}$, conforme quadro a seguir, o que demonstra o grande retrocesso ao qual foi submetida a Educação Básica. Ressalta-se, nesse sentido, que os PCN, ainda que de forma superficial, determinavam as habilidades e competências das áreas e seus respectivos componentes curriculares, o que não acontece com a BNCC. 
QUADRO COMPARATIVO ENTRE OS PCN E A $3^{\text {a }}$ VERSÃO DA BNCC DO ENSINO MÉDIO

\begin{tabular}{|c|c|c|}
\hline Categoria & $P C N$ & $B N C C$ \\
\hline O que explicita & $\begin{array}{l}\text { Capacidades que devem ser desenvolvidas } \\
\text { pelos alunos ao longo da escolaridade. } \\
\text { (BRASIL, 1997b, p. 47) }\end{array}$ & $\begin{array}{l}\text { Competências que os alunos devem } \\
\text { desenvolver ao longo de toda a Educação } \\
\text { Básica e em cada etapa da escolaridade } \\
\text { (BRASIL, 2018, p. 23) }\end{array}$ \\
\hline $\begin{array}{l}\text { Definição } \\
\text { competências }\end{array}$ & $\begin{array}{l}\text { Capacidades que permitam produzir e } \\
\text { usufruir dos bens culturais, sociais e } \\
\text { econômicos, passando a incluir } \\
\text { procedimentos, valores, normas e atitudes. } \\
\text { (BRASI, 1997b, p. 51) }\end{array}$ & $\begin{array}{l}\text { Mobilização de conhecimentos (conceitos } \\
\text { e procedimentos), habilidades (práticas, } \\
\text { cognitivas e socioemocionais), atitudes e } \\
\text { valores para resolver demandas complexas } \\
\text { da vida cotidiana, do pleno exercício da } \\
\text { cidadania e do mundo do trabalho. } \\
\text { (BRASIL, 2018, p. 8) }\end{array}$ \\
\hline $\begin{array}{l}\text { Objetivo da Área } \\
\text { de Ciências } \\
\text { Humanas }\end{array}$ & $\begin{array}{l}\text { Deve-se desenvolver a tradução do } \\
\text { conhecimento das Ciências Humanas em } \\
\text { consciências críticas e criativas, capazes de } \\
\text { gerar respostas adequadas a problemas } \\
\text { atuais e a situações novas (BRASIL, 2000a } \\
\text { p. 21) }\end{array}$ & $\begin{array}{l}\text { Pretende possibilitar o acesso a conceitos, } \\
\text { dados e informações que permitam aos } \\
\text { estudantes atribuir sentidos aos } \\
\text { conhecimentos da área e utilizá-los } \\
\text { intencionalmente para a compreensão, a } \\
\text { crítica e o enfrentamento ético dos } \\
\text { desafios do dia a dia, de determinados } \\
\text { grupos e de toda a sociedade. (BRASIL, } \\
2018, \text { p. 550) }\end{array}$ \\
\hline $\begin{array}{l}\text { Competência da } \\
\text { Área de Ciências } \\
\text { Humanas }\end{array}$ & $\begin{array}{l}\text { Traduzir os conhecimentos sobre a pessoa, } \\
\text { a sociedade, a economia, as práticas } \\
\text { sociais e culturais em condutas de } \\
\text { indagação, análise, problematização e } \\
\text { protagonismo diante de situações novas, } \\
\text { problemas ou questões da vida pessoal, } \\
\text { social, política, econômica e cultural. } \\
\text { (BRASIL, 2000a, p. 14) }\end{array}$ & $\begin{array}{l}\text { Analisar processos políticos, econômicos, } \\
\text { sociais, ambientais e culturais nos âmbitos } \\
\text { local, regional, nacional e mundial em } \\
\text { diferentes tempos, a partir de } \\
\text { procedimentos epistemológicos } \\
\text { científicos, de modo a compreender e } \\
\text { posicionar-se criticamente com relação a } \\
\text { esses processos e às possíveis relações } \\
\text { entre eles. (BRASIL, 2018, p. 558) }\end{array}$ \\
\hline $\begin{array}{l}\text { Competência da } \\
\text { Área de Ciências } \\
\text { Humanas }\end{array}$ & $\begin{array}{l}\text { Compreender o desenvolvimento da } \\
\text { sociedade como processo de ocupação de } \\
\text { espaços físicos e as relações da vida } \\
\text { humana com a paisagem, em seus } \\
\text { desdobramentos políticos, culturais, } \\
\text { econômicos e humanos. (BRASIL, 2000a, } \\
\text { p. 19) }\end{array}$ & $\begin{array}{l}\text { Contextualizar, analisar e avaliar } \\
\text { criticamente as relações das sociedades } \\
\text { com a natureza e seus impactos } \\
\text { econômicos e socioambientais, com vistas } \\
\text { à proposição de soluções que respeitem e } \\
\text { promovam a consciência e a ética } \\
\text { socioambiental e o consumo responsável } \\
\text { em âmbito local, regional, nacional e } \\
\text { global. (BRASIL, 2018, p. 562) }\end{array}$ \\
\hline
\end{tabular}

FONTE: Morello; Horn (2018)

Outra questão importante a ser ressaltada, é que é possível, pelos documentos publicados, tais como a BNCC para a educação infantil e o ensino fundamental, assim como pelas diversas orientações quanto ao seu processo de implementação ${ }^{21}$, afirmar que a BNCC é, não só um retrocesso às políticas anunciadamente neoliberais, mas piorada no sentido de

\footnotetext{
${ }^{21}$ Apresentações e orientações utilizadas pelo Ministério da Educação, às quais estão disponíveis nos sites do Consed, Undime, Movimento todos pela base, o guia de implementação da BNCC, disponível em http://implementacaobncc.com.br/, entre outros.
} 
que, em comparação aos $\mathrm{PCN}^{22}$, a $\mathrm{BNCC}$ é obrigatória e amarra sua implementação com outras ações e políticas, que influenciam diretamente no movimento de elaboração do currículo, quais sejam: o estabelecimento de ações com relação à governança e ao regime de colaboração, a exigência de que as redes (estadual, municipal e privadas) reelaborem seus currículos, a adequação dos livros e materiais didáticos frente às habilidades e competências impostas, principalmente via exigência de sua consolidação no edital do Programa Nacional do Livro Didático (PNLD), a formação inicial e continuada de professores ${ }^{23}$ e no controle, relacionado por ações de avaliação e monitoramento deste processo, assim como na adequação dos sistemas de avaliação em larga escala. Essas ações acabam por 'fechar o cerco' com relação às possibilidades de enfrentamento e resistência às concepções impostas e de propostas curriculares que não corroborem com tais concepções.

\section{Considerações finais}

Por compreender que as relações sociais são permeadas por movimentos dialéticos, entende-se que, ao mesmo tempo em que as práticas sociais são alienantes e alienadas, estas também integram as condições objetivas e subjetivas para sua superação. Isso requer, entre outras coisas, além da apropriação daquilo que constitui e caracteriza a humanidade, "uma tomada de posição ética e política pela superação da alienação" (DUARTE, 2013, p. 68).

Partindo desse pressuposto, convém retomar que no cotidiano, o homem age de forma instintiva e inconsciente. "Nesta o indivíduo cria para si relações, baseado na própria experiência, nas próprias possibilidades, na própria atividade e daí considerar esta realidade como sendo o seu próprio mundo" (Grifo do autor. KOSIK, 2010, p. 80). Um mundo construído na realidade concreta, mas subvertido pela divisão social do trabalho, na impessoalidade e nas relações fetichizadas que estabelece com suas produções e ações, como se estes fossem coisas externas e não socialmente produzidas. Na sociedade alienada,

as relações sociais assumem a aparência de forças naturais às quais os indivíduos se submetem, interiorizando-as por meio de uma identificação espontânea com a situação dada [...]. É condição indispensável para a realização plena da liberdade do gênero humano que os seres humanos submetam as relações sociais objetivadas ao seu controle consciente. (DUARTE, 2013, p. 80)

\footnotetext{
22 Estes se definiam apenas como orientações e linhas gerais para a elaboração curricular.

${ }^{23}$ Principalmente no que concerne às alterações da estrutura de formação ofertada pelos cursos de licenciatura, já iniciadas pelo Programa de Residência Pedagógica.
} 
Entretanto, Duarte (2013, p. 89) explicita que a atividade consciente também pode ser alienada, na medida em que as atividades humanas podem ser desdobradas em ações que nem sempre mantém "uma relação imediata entre o objeto sobre o qual o ser humano age e o motivo pelo qual está agindo”. Em outras palavras, a ação docente prevê ações intencionais e conscientes para que os estudantes se apropriem dos conteúdos escolares. Todavia, a ação de ensinar aos alunos, apesar de pressupor uma ação consciente por parte do professor, este pode realizá-la de forma a não perceber que aquele conteúdo é, ele próprio, uma produção social humana e historicamente elaborada.

Diante disso, "a atividade humana, por ser uma atividade consciente, pode, portanto, decompor-se em ações cujo sentido não é dado por elas mesmas, mas pela relação com o motivo da atividade" (DUARTE, 2013, p. 93). Nessa perspectiva, o trabalho educativo pode, ao mesmo tempo, ser uma ação que humanize ou aliene o indivíduo, se constituindo como limite, mas também como possibilidade de superação desta alienação.

Justamente por considerar o movimento dialético de produção e reprodução social é que se pode (e deve-se) buscar a emancipação humana, embasado na prerrogativa de que é necessário fazer o melhor possível, a partir da realidade concreta e objetiva nas quais as relações de ensino-aprendizagem acontecem. Agir na contradição é, também, um processo de resistência. Ou, em outras palavras, "a coincidência entre a altera[ção] das circunstâncias e a atividade ou automodificação humanas só pode ser apreendida e racionalmente entendida como prática revolucionária” (MARX; ENGELS, 2017, p.534)

A partir das considerações realizadas, pode-se considerar, inicialmente, que a filosofia, entendida a partir do estatuto de disciplina escolar, com conteúdos socialmente referendados, pode contribuir com o processo de humanização dos indivíduos, na medida em que pode se constituir como ação consciente para superar a práticas alienantes e alienadas.

Entretanto, para que isso ocorra, deve problematizar questões que se valem da historicidade do pensamento filosófico para possibilitar a reelaboração, a ressignificação ou reificação de 'pré' conceitos, superando o senso comum em uma reflexão crítica e radical acerca dos objetos estudados.

Nessa perspectiva, "ensinar filosofia consiste em cativar o aluno transformando o estudo filosófico num trabalho de investigação que procura conhecer o discurso do outro para conhecer-se a si mesmo" (SCHLESENER, 2013, p. 9). Em outras palavras, só se pode “aprender a pensar, pensando, mas, para nós, pensar implica retomar aquilo que é resultante do já pensado" (SEVERINO, 1998, p. 4).

Outra questão importante é que as atividades e os encaminhamentos realizados devem 
possibilitar aos estudantes pensarem por si próprios. Eles não devem estimular a reprodução de conceitos apresentados como um 'copia e cola' daquilo que já foi 'pensado', mas estimular o pensamento crítico e a elaboração pessoal.

A necessidade do fazer em filosofia que se expressa como produção do pensar, dito e escrito, onde ele concretiza o domínio das atividades básicas do pensamento, que são o conceituar, o problematizar e o argumentar. (SEVERINO, 1998, p. 5).

Diante disso, o processo de 'ensino-aprendizagem' da disciplina de filosofia apresenta inúmeros desafios, seja pela educação escolar e suas condições estruturais e políticas, que englobam a problemática da formação dos professores, das condições de trabalho e dos recursos didáticos disponíveis, seja pelo próprio entendimento do que é a filosofia enquanto disciplina escolar, seja pela definição de seus conteúdos e métodos.

Cabe, nesse sentido, ressaltar que, por mais que existam divergências quanto à questão epistemológica da filosofia, devemos reiterar que, para atender aos objetivos de uma educação crítica e emancipatória, a disciplina escolar de filosofia deve superar a reprodução, para dialeticamente problematizar questões inerentes à existência humana, como possibilidade de transformação da realidade, da existência e das relações que se estabelece com os outros e consigo mesmo.

\section{REFERÊNCIAS}

BRASIL. Constituição (2009). Emenda Constitucional no 59, de 11 de novembro de 2009. Acrescenta $\S 3^{\circ}$ ao art. 76 do Ato das Disposições Constitucionais Transitórias para reduzir, anualmente, a partir do exercício de 2009, o percentual da Desvinculação das Receitas da União incidente sobre os recursos destinados à manutenção e desenvolvimento do ensino de que trata o art. 212 da Constituição Federal, dá nova redação aos incisos I e VII do art. 208, de forma a prever a obrigatoriedade do ensino de quatro a dezessete anos e ampliar a abrangência dos programas suplementares para todas as etapas da educação básica, e dá nova redação ao $\S$ $4^{\circ}$ do art. 211 e ao $\S 3^{\circ}$ do art. 212 e ao caput do art. 214, com a inserção neste dispositivo de inciso VI.. Emenda Constitucional N 59/2009. Brasília, 2009a.

Lei $\mathrm{n}^{\circ}$ 9.394, de 20 de dezembro de 1996. Estabelece as diretrizes e bases da educação nacional. Lei no 9.394/96. Brasília, 1996.

Lei $\mathrm{n}^{\mathrm{o}}$ 11.684, de 02 de junho de 2008. Inclui a Filosofia e a Sociologia como disciplinas obrigatórias nos currículos do ensino médio. Lei n⿳0 11.684/2008. Brasília, 2008.

Lei $\mathrm{n}^{\circ} 13.415$, de 16 de fevereiro de 2017. Altera as Leis $\mathrm{n}^{\circ} \mathrm{s} 9.394$, de 20 de dezembro de 1996, 11.494, de 20 de junho 2007, a Consolidação das Leis do Trabalho - CLT, aprovada pelo Decreto-Lei $n^{\circ} 5.452$, de $1^{\circ}$ de maio de 1943, e o Decreto-Lei $n^{\circ} 236$, de 28 de 
fevereiro de 1967; revoga a Lei $\mathrm{n}^{\circ} 11.161$, de 5 de agosto de 2005; e institui a Política de Fomento à Implementação de Escolas de Ensino Médio em Tempo Integral. Lei no 13.415/2017. Brasília, 2017a.

Projeto de Lei $n^{\circ}$ 6.840, de 2013. Altera a Lei $n^{\circ}$ 9.394, de 20 de dezembro de 1996, que estabelece as diretrizes e bases da educação nacional, para instituir a jornada em tempo integral no ensino médio, dispor sobre a organização dos currículos do ensino médio em áreas do conhecimento e dá outras providências. PL N $\mathbf{N}^{\mathbf{6}} \mathbf{6 4 0 / 2 0 1 3}$. Brasília, 2013.

Medida Provisória $\mathrm{n}^{\mathrm{o}}$ 746, de 23 de setembro de 2016. Institui a Política de Fomento à Implementação de Escolas de Ensino Médio em Tempo Integral, altera a Lei $\mathbf{n}^{\circ}$ 9.394, de 20 de dezembro de 1996, que estabelece as diretrizes e bases da educação nacional, e a Lei $n^{\text {o }} 11.494$ de 20 de junho 2007, que regulamenta o Fundo de Manutenção e Desenvolvimento da Educação Básica e de Valorização dos Profissionais da Educação, e dá outras providências. MP n⿳0 746/2016. Brasília, 2016.

. Parecer $\mathrm{n}^{\circ}$ 05, de 04 de maio de 2011. Diretrizes Curriculares Nacionais para o Ensino Médio. Parecer nº 05/2011 - CNE/CEB. Brasília, 2011.

Secretaria de Educação Fundamental. Parâmetros curriculares nacionais: introdução aos parâmetros curriculares nacionais. Brasília: MEC/SEF, 1997b.

Ministério da Educação. Parâmetros curriculares nacionais (ensino médio): parte I - bases legais. Brasília: MEC, 2000a.

Ministério da Educação. Parâmetros curriculares nacionais (ensino médio): parte IV - ciências humanas e suas tecnologias. Brasília: MEC, $2000 \mathrm{~b}$.

Ministério da Educação. PCN+ ensino médio: orientações educacionais complementares aos parâmetros curriculares nacionais: ciências humanas e suas tecnologias. Brasília: MEC, 2002.

Secretaria de Educação Básica. Orientações curriculares para o ensino médio: ciências humanas e suas tecnologias. Vol. 3. Brasília: MEC/SEB, 2006.

. Secretaria de Educação Básica. Base Nacional Comum Curricular: 1a Versão. Brasília: MEC/SEB, 2015.

Secretaria de Educação Básica. Base Nacional Comum Curricular: 2a Versão. Brasília: MEC/SEB, 2016b.

Secretaria de Educação Básica. Base nacional comum curricular: educação infantil e ensino fundamental. Brasília: MEC/SEB, 2017c.

Secretaria de Educação Básica. Base nacional comum curricular: ensino médio. Versão preliminar. Brasília: MEC/SEB, 2018.

DELORS, J. Educação: um tesouro a descobrir. Relatório para a UNESCO da comissão internacional sobre educação para o século XXI. Brasília: MEC/UNESCO, 2010. 
DUARTE, N. Limites e contradições da cidadania na sociedade capitalista. Pro-posições, Campinas, v. 21, n. 161, p.75-87, jan/abr, 2010.

. Vigotski e o "aprender a aprender": crítica às apropriações neoliberais e pósmodernas da teoria vigotskiana. 5 ${ }^{\mathrm{a}}$ ed. ver. Campinas: Autores Associados, 2011.

. et al. O marxismo e a questão dos conteúdos escolares. In: IX Seminário Nacional de Estudos e Pesquisas "História, Sociedade e Educação no Brasil". João Pessoa, 2012. Anais Eletrônicos. João Pessoa: Universidade Federal da Paraíba, 2012, p. 3953-3979.

A individualidade para si: Contribuição a uma teoria histórico-crítica da formação do indivíduo. 3. ed. Campinas: Editores Associados, 2013.

Os conteúdos escolares e a ressurreição dos mortos: contribuição à teoria histórico-crítica. Campinas: Autores Associados, 2016.

EAGLETON, T. As ilusões do pós-modernismo. Rio de Janeiro: Zahar, 1996.

ETGES, N. J. Ciência, interdisciplinaridade e educação. In: JANTSCH, A. P.; BIANCHETTI, L. (Org.). Interdisciplinaridade: para além da filosofia do sujeito. 9. ed. Petrópolis: Vozes, 2011. Cap. 3. p. 60-94.

FOLLARI, R. A. Interdisciplina e dialética: sobre um mal-entendido. In: JANTSCH, A. P.; BIANCHETTI, L. (Org.). Interdisciplinaridade: para além da filosofia do sujeito. 9. ed. Petrópolis: Vozes, 2011. Cap. 3. p. 122-137.

FRIGOTTO, G. A interdisciplinaridade como necessidade e como problema nas ciências sociais. In: JANTSCH, A. P.; BIANCHETTI, L. (Org.). Interdisciplinaridade: para além da filosofia do sujeito. 9. ed. Petrópolis: Vozes, 2011. Cap. 3. p. 122-137.

HARVEY, D. Condição pós-moderna. São Paulo: Edições Loyola, 2017.

KOSIK, K. Dialética do concreto. $2^{\text {a }}$ ed. Rio de Janeiro: Paz e Terra, 2010.

MALACHEN, J. Cultura, conhecimento e currículo: contribuições da pedagogia históricocrítica. Campinas: Autores Associados, 2016.

MARX, K.; ENGELS, F. A ideologia alemã: crítica da mais recente filosofia alemã em seus representantes Feuerbach, B. Bauer e Stiner, e do socialismo alemão em seus diferentes profetas (1845-1846). São Paulo: Boitempo, 2017.

MELLO, G. N. Currículo da educação básica no Brasil: concepções e políticas. São Paulo: Movimento Pela Base, 2014.

Disponível em: <http://movimentopelabase.org.br/wpcontent/uploads/2015/09/guiomar_pesquisa.pdf>. Acesso em: 08 set. 2018.

MÉSZAROS, I. A educação para além do capital. $2^{\text {a }}$ ed. São Paulo: Boitempo, 2008.

MOREIRA, A. F. B. A psicologia... e o resto: o currículo segundo César Coll. Cadernos de Pesquisa, São Paulo, v. 1, n. 100, p.93-107, mar. 1997. 
SCHLESENER, A. H. Ensinar Filosofia ou Ensinar a pensar? O Desafio Kantiano na Realidade do Ensino Médio. In: Revista do NESEF Filosofia e Ensino. Desafios epistemológicos e políticos da filosofia na escola básica. Curitiba, UFPR, vol. $3, \mathrm{n}^{\circ} 3$ jun/jul/ago/set 2013. Disponível em: http://dx.doi.org/10.5380/nesef.v3i3. Acesso em outubro/2017.

SEVERINO, J. A. O ensino da filosofia: algumas notas sobre seus desafios atuais. In: Semana de Filosofia. Departamento de Filosofia da PUC-SP. Texto de exposição em mesa redonda. São Paulo: PUCSP, 1998.

SHIROMA, E. O; EVANGELISTA, O. Um fantasma ronda o professor: a mística da competência. In: MORAES, M. C. M. (Org.). Iluminismo às avessas: produção de conhecimento e políticas de formação docente. Rio de Janeiro: DP\&A, 2003. p. 81-98.

Recebido: agosto/2018

Aprovado: novembro/2018 